Article

\title{
Cytotoxic Potential of the Coelomic Fluid Extracted from the Sea Cucumber Holothuria tubulosa against Triple-Negative MDA-MB231 Breast Cancer Cells
}

\author{
Claudio Luparello*(D), Debora Ragona, Dalia Maria Lucia Asaro, Valentina Lazzara, \\ Federica Affranchi, Monica Celi, Vincenzo Arizza ${ }^{(D)}$ and Mirella Vazzana \\ Dipartimento di Scienze e Tecnologie Biologiche, Chimiche e Farmaceutiche (STEBICEF), Università di Palermo, \\ Viale delle Scienze, 90128 Palermo, Italy; debora0410ale@gmail.com (D.R.); daliaasaro@libero.it (D.M.L.A.); \\ valentina.lazzara@community.unipa.it (V.L.); federica.affranchi@community.unipa.it (F.A.); \\ monica.celi@unipa.it (M.C.); vincenzo.arizza@unipa.it (V.A.); mirella.vazzana@unipa.it (M.V.) \\ * Correspondence: claudio.luparello@unipa.it; Tel.: +39-91-238-97405
}

Received: 29 August 2019; Accepted: 5 October 2019; Published: 9 October 2019

check for updates

\begin{abstract}
Growing evidence has demonstrated that the extracts of different holothurian species exert beneficial effects on human health. Triple negative breast cancers (TNBC) are highly malignant tumors that present a poor prognosis due to the lack of effective targeted therapies. In the attempt to identify novel compounds that might counteract TNBC cell growth, we studied the effect of the exposure of the TNBC cell line MDA-MB231 to total and filtered aqueous extracts of the coelomic fluid obtained from the sea cucumber Holoturia tubulosa, a widespread species in the Mediterranean Sea. In particular, we examined cell viability and proliferative behaviour, cell cycle distribution, apoptosis, autophagy, and mitochondrial metabolic/cell redox state. The results obtained indicate that both total and fractionated extracts are potent inhibitors of TNBC cell viability and growth, acting through both an impairment of cell cycle progression and mitochondrial transmembrane potential and a stimulation of cellular autophagy, as demonstrated by the increase of the acidic vesicular organelles and of the intracellular protein markers beclin-1, and total LC3 and LC3-II upon early exposure to the preparations. Identification of the water-soluble bioactive component(s) present in the extract merit further investigation aiming to develop novel prevention and/or treatment agents efficacious against highly metastatic breast carcinomas.
\end{abstract}

Keywords: Holothuria tubulosa; coelomic fluid; breast cancer; cell viability; cell cycle; mitochondrial function; autophagy

\section{Introduction}

Holothurians, also named sea cucumbers, belong to the class Holothuroidea (phylum Echinodermata), which includes around 1250 described living species worldwide. Holothurians have been widely studied in the last two decades for their high nutritious value and beneficial effects on human health [1-3], which have made them an object of investigation for possible therapeutic uses. In fact, the efficacy of holothurians to alleviate a number of different pathologies (asthma, rheumatism, hypertension, impotence, and others) is well known from Asian traditional medicine, as reported in the literature $[4,5]$. Furthermore, growing evidence has demonstrated that the extracts of different holothurian species are endowed with several varied biological and pharmacological properties, spanning from anti-angiogenic and anticancer to antimicrobial and anticoagulant activities (e.g., $[1,6,7]$ ). Such effects have been ascribed to the presence of numerous bioactive compounds among which the most characterized to date are the triterpene glycosides saponins, accounting for 
more than 300 different molecules, along with components of various macromolecular nature, such as glycosaminoglycans, phenolics, and peptides [8].

Triple-negative breast cancers (TNBC) are "aggressive" and highly malignant tumors characterized by the lack of expression of estrogen-, progesterone-, and epidermal growth factor type 2 (HER2) receptors, thereby being poorly responsive to hormonal therapies and to HER2-targeting drugs. This makes the TNBC histotype usually associated with worse prognosis than other breast tumors [9]. The limitation of treatment options against TNBC has prompted multiple approaches attempting to identify novel compounds that might counteract neoplastic cell growth. On the other hand, a thorough biological characterization of such compounds and the elucidation of their molecular mechanism of action is a necessary aspect for the development of targeted therapies.

The sea cucumber Holothuria tubulosa is a widespread species in the Mediterranean Sea and one of the main species receiving rising commercial interest, being a seafood rich with nutrients and suitable for human consumption [10]. Dealing with biomedical applications, methanol extracts of this marine invertebrate were shown to restrain the inflammatory process in experimentally oedematous mice [11]. More recent studies have highlighted that coelomocytes, the immune mediator cells contained in the coelomic fluid (CF) of the animal, represent a source of antimicrobial substances and diffusible haemolytic factors active on rabbit and sheep erythrocytes [12,13]. These findings prompted an expansion of the investigation on the pharmacological potential of $H$. tubulosa-derived components, whose massive procurement represents an easy task due to the extensive dissemination of this aquatic organism.

In the present study, we examined the effect of the exposure of the TNBC cell line MDA-MB231 to total and filtered aqueous extracts of the CF obtained from $\mathrm{H}$. tubulosa. The cell line chosen as the model system for this investigation is derived from a pleural effusion of a TNBC of basal subtype and displays several characteristics related to a highly malignant phenotype, such as the inactivation of p53 due to a mutation in codon 280 of exon 8, and the ability to form metastases in vivo [14-16]. In particular, our goal was to examine in a comprehensive fashion the CF extract-mediated modulation, if present, of viability and proliferative behaviour, cell cycle distribution, apoptosis and autophagy events, and mitochondrial metabolic/cell redox state. The results obtained indicate that both total and fractionated CF extracts are potent inhibitors of TNBC cell growth acting through both an impairment of cell cycle progression and mitochondrial respiration and a stimulation of cellular autophagy.

\section{Materials and Methods}

\subsection{Catching and Safekeeping of the Animals}

A sample of 120 mature sea cucumbers (Holothuria tubulosa, Figure 1), approximately $11 \pm 0.98 \mathrm{~cm}$ in length with a body weight of $46 \pm 7.5 \mathrm{~g}$, was collected from the Gulf of Palermo (Sicily, Italy) at a depth of 5-10 m, near a grassland of Posidonia oceanica, and the animals were manipulated after 2 weeks of acclimation in an aquarium filled with artificial sea water $(0.425 \mathrm{M} \mathrm{NaCl} ; 9 \mathrm{mM} \mathrm{KCl}$; $9.3 \mathrm{mM} \mathrm{CaCl}_{2} \cdot 2 \mathrm{H}_{2} \mathrm{O} ; 0.0255 \mathrm{M} \mathrm{MgSO}_{4} \cdot 7 \mathrm{H}_{2} \mathrm{O} ; 0.023 \mathrm{MgCl}_{2} \cdot 6 \mathrm{H}_{2} \mathrm{O} ; 2 \mathrm{mM} \mathrm{NaHCO}_{3} \mathrm{pH} 8.0$ ) at $15 \pm 2{ }^{\circ} \mathrm{C}$ with constant oxygenation. The animals were fed with commercial invertebrate food (Algamac 3000, Aquafauna Bio-Marine Inc., Hawthorne, CA, USA).

\subsection{Bleeding Procedure and Preparation of CF Extracts}

The animals were cut making an incision measuring $3-5 \mathrm{~cm}$ on the anterior-dorsal side using a scalpel, paying specific attention not to injure the internal organs. The $\mathrm{CF}$ was collected in several plastic beakers covered by a filter, kept on ice, and then transferred to polycarbonate tubes and immediately centrifuged at $1000 \mathrm{~g}$ for $10 \mathrm{~min}$ at $4{ }^{\circ} \mathrm{C}$ to remove the coelomocytes. Once separated from the cellular component, an aliquot of $\mathrm{CF}$ was stored at $-80{ }^{\circ} \mathrm{C}$ and the remaining volume was filtered using Corning Spin-X UF 6 concentrators equipped with polyethersulfone membranes (10K MWCO; Corning Inc., Tewksbury, MA, USA). The tubes were centrifuged at maximum speed (4000 g) for approximately 
3-4 h at $4{ }^{\circ} \mathrm{C}$, and the filtered $\mathrm{CF}$ was stored at $-80^{\circ} \mathrm{C}$. Then, both the total and filtered CFs, hereafter referred to as total extract and 10K fraction, respectively, were lyophilized in an Alpha 2-4 LD plus freeze-dryer (Martin Christ, Osterode am Harz, D). Aliquots of total extracts and 10K fractions were resuspended in the minimum volume of sterile distilled water and the protein concentration was measured with the Qubit Protein Assay Kit in the Qubit 3.0 fluorometer (ThermoFisher, Waltham, MA, USA), according to the manufacturer's instructions.

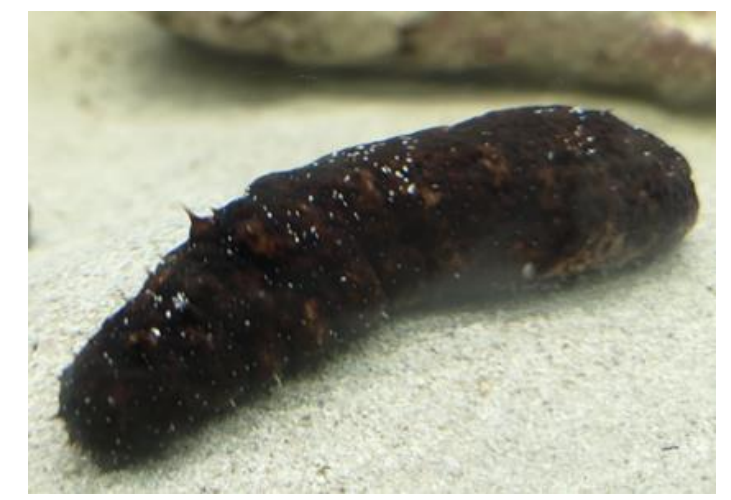

Figure 1. A specimen of Holoturia tubulosa sea cucumber.

\subsection{Cell Cultures}

MDA-MB231 TNBC cells were cultured in D-MEM medium purchased from Sigma, St. Louis, MO, USA, supplemented with $10 \%$ foetal calf serum (FCS; ThermoFisher) and antibiotic/antimycotic mixture (100 U/mL penicillin, $100 \mu \mathrm{g} / \mathrm{mL}$ streptomycin, and $2.5 \mathrm{mg} / \mathrm{L}$ amphotericin B; ThermoFisher) at $37^{\circ} \mathrm{C}$ in a $5 \% \mathrm{CO}_{2}$ atmosphere.

\subsection{MTT Assay}

Cell viability was assessed by an MTT assay [17]. Briefly, MDA-MB231 cells in exponential growth were plated at a concentration of 5500 cells/well in a 96-well plate, allowed to adhere overnight, and then treated with different concentrations of total extracts and 10K fractions for either 24 or $48 \mathrm{~h}$. After addition of MTT and incubation with the solubilization buffer, the absorbance of the dissolved formazan was measured in an automated microplate reader $(\lambda=550 \mathrm{~nm})$. Cell viability ratio between treated cells and controls was determined and the half maximal inhibitory concentrations $\left(\mathrm{IC}_{50}\right)$ evaluated with the online $\mathrm{IC}_{50}$ calculator available at https://www.aatbio.com/tools/ic50-calculator (accessed June 2019).

\subsection{Flow Cytometry}

Flow cytometric assays were performed on treated and control cells as described in [18,19], using a FACSCanto instrument (BD Biosciences, Franklin Lakes, NJ, USA). All the data were analyzed with Flowing Software v.2.5.1. Gating in the FSC vs. SSC plot was performed before the specific analyses to exclude debris, which displayed low FSC values.

For the analysis of cell cycle distribution, cells were fixed with cold $70 \%$ ethanol, incubated with $40 \mu \mathrm{g}$ RNase $\mathrm{A} / \mathrm{mL}$, and stained with $20 \mu \mathrm{g}$ propidium iodide/mL.

The externalization of phosphatidylserine, a hallmark of apoptotic events, was checked with the Annexin V-FITC kit (Canvax Biotech, Cordoba, Spain) according to the manufacturer's instructions.

The transmembrane mitochondrial potential (MMP) was checked using the mitochondria-selective dye JC1 (Molecular Probes, Eugene, OR, USA), which undergoes a fluorescence emission shift from green $(\sim 529 \mathrm{~nm})$ to red $(\sim 590 \mathrm{~nm})$ in case of physiologic MMP, whereas, in case of loss of MMP, a decrease in the red/green fluorescence intensity ratio can be observed. A valinomycin-treated positive control was included in the analysis. 
The production of reactive oxygen species (ROS) was evaluated using the ROS Detection Assay Kit (Canvax Biotech) following the manufacturer's instructions. $\mathrm{A}_{2} \mathrm{O}_{2}$-treated positive control was included in the analysis.

The modulation of the autophagic behavior was checked via the flow cytometric quantification of i) the acidic vesicular organelles (AVOs), and ii) the autophagic markers beclin- 1 and microtubuleassociated protein light chain-3 (LC3), both total and as LC3-II form. For i), after cell fixing with cold 70\% ethanol, cells were stained with $100 \mu$ g acridine orange/mL (Sigma) for 20 min in the dark. For ii), two different procedures were followed in the case of either beclin-1 and total LC-3 or LC3-II quantitation. For beclin-1 and total LC3 detection, cells were fixed with HistoChoice (Amresco, Solon, $\mathrm{OH}, \mathrm{USA}$ ) for $30 \mathrm{~min}$ at ambient temperature, washed with $2 \%$ FCS-containing phosphate-buffered saline (PBS), and incubated with the primary antibody dissolved in $0.1 \%$ Triton X-100 + $2 \%$ FCS + $40 \mu \mathrm{g}$ propidium iodide/ $\mathrm{ml}$ in PBS for $30 \mathrm{~min}$. The antibodies used in the present study were rabbit polyclonal anti-beclin-1 (H-300, sc-11427, Santa Cruz Biotechnology, Dallas, TX, USA; working dilution 1:50, as recommended by He et al. [20]) and rabbit polyclonal anti-LC3 (L8918, Sigma; working dilution 1:250). Negative controls were prepared with the omission of the primary antibody. After exhaustive washing, the samples were incubated for $30 \mathrm{~min}$ with the secondary antibody (FITC-conjugated goat anti-rabbit IgG whole molecule, F0382, Sigma; working dilution 1:80), washed three times in PBS, and submitted to flow cytometry. For LC3-II detection, according to the procedure described by Eng et al. [21], unfixed cells were rinsed with PBS $+0.05 \%$ saponin (Sigma) to allow the extraction of the non-autophagosome-associated soluble LC3-I, and then incubated with the primary and secondary antibodies as previously reported in this paragraph, with the exception that saponin was always present in the antibody dilution buffers and replaced Triton X-100.

\subsection{Statistics}

Statistics were checked through ANOVA test with SigmaPlot 11.0 software (SYSTAT, San Jose, CA, USA). A $p$-value $<0.05$ was considered statistically significant.

\section{Results}

In a first set of experiments, we checked the effect of dose- and time-dependent incubation with total extracts and $10 \mathrm{~K}$ fractions on MDA-MB231 cell survival and growth via MTT assay. As shown in Figure 2, when cells were exposed for $24 \mathrm{~h}$ and $48 \mathrm{~h}$ to both samples, they underwent a concentration-dependent decrease of cell viability and proliferation. At the highest concentration tested, i.e., $15 \mu \mathrm{g} / \mathrm{mL}$, the $10 \mathrm{~K}$ fraction was more potent than the total extract in inhibiting cell viability and growth after both 24 and $48 \mathrm{~h}$ of incubation. The average $\mathrm{IC}_{50}$ was found to be 12.6 and $11.15 \mu \mathrm{g} / \mathrm{mL}$ at $24 \mathrm{~h}$ exposure and 10.1 and $10.45 \mu \mathrm{g} / \mathrm{mL}$ at $48 \mathrm{~h}$ exposure for the total extract and $10 \mathrm{~K}$ fraction, respectively. Once the cytotoxicity of the two preparations on MDA-MB231 cells was confirmed, all the subsequent experiments were performed after cell exposures to total extracts and $10 \mathrm{~K}$ fractions at the corresponding $\mathrm{IC}_{50}$ for 24 and $48 \mathrm{~h}$.

In order to get more insight into the biological basis of the cytotoxic activity exerted by the total extracts and 10K fractions on triple-negative MDA-MB231 cells, we checked their effects on cell cycle distribution, apoptosis induction via evaluation of phosphatidylserine externalization, mitochondrial transmembrane potential (MMP) state, ROS production, and autophagy modulation, the latter via quantitation of the acidic vesicular organelles (AVOs) and of specific intracellular biochemical markers, i.e., beclin-1, total LC3 and LC3-II.

First, we tested which kind of perturbation was induced by treatments on MDA-MB231 cell cycle. Figure 3 shows that, when compared to the control, $48 \mathrm{~h}$ exposure to both preparations induced an accumulation of cells in $\mathrm{S}$ phase fraction, more conspicuous for $10 \mathrm{~K}$ fraction (control vs. total extract vs. $10 \mathrm{~K}$ fraction $=5.43 \%$ vs. $17.7 \%$ vs. $23.5 \%$ ), and a decrease of $\mathrm{G}_{2} / \mathrm{M}$ fraction (control vs. total extract vs. $10 \mathrm{~K}$ fraction $=59.48 \%$ vs. $46.6 \%$ vs. $47.2 \%$ ). In addition, the $10 \mathrm{~K}$ fraction determined a decrease also of the $G_{0} / G_{1}$ fraction (control vs. $10 \mathrm{~K}$ fraction $=33.91 \%$ vs. $26.53 \%$ ), which was not observed after 
exposure to the total fraction. No modification of cell distribution in the cycle phases was recorded at $24 \mathrm{~h}$ exposure to both preparations with respect to control.

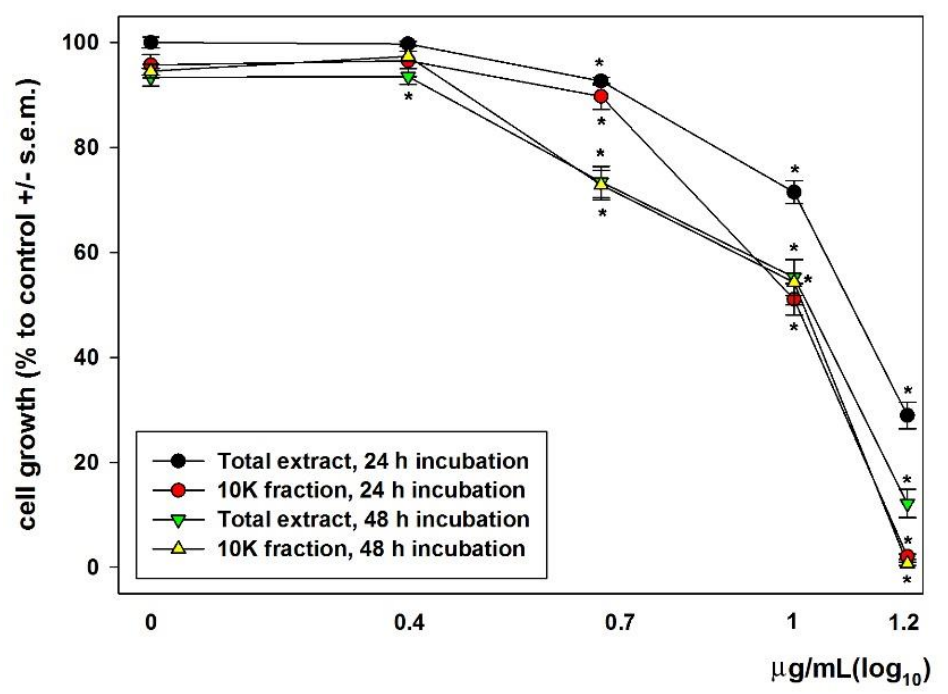

Figure 2. Dose response effect of total extracts and $10 \mathrm{~K}$ fractions on the viability and growth of MDA-MB231 cells after either 24 or $48 \mathrm{~h}$ of exposure. Error bars correspond to the standard error of the mean (s.e.m.) of three independent measurements. ${ }^{*} p<0.05$.

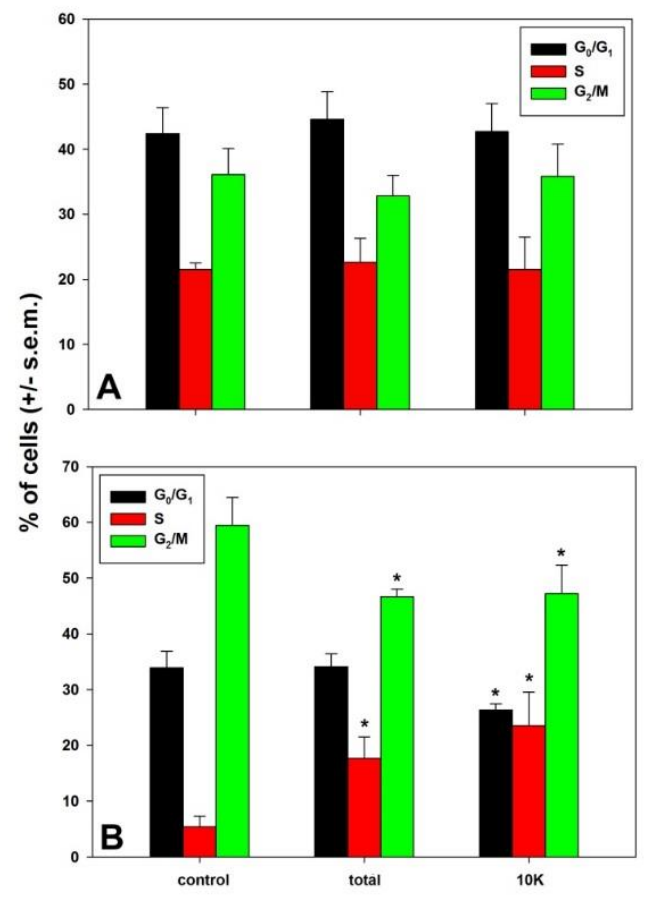

Figure 3. Cell cycle distribution of MDA-MB-231 cells exposed to total extracts and 10K fractions for 24 (A) and $48 \mathrm{~h}$ (B), compared to control conditions. Error bars correspond to the standard error of the mean (s.e.m.) of three independent measurements. ${ }^{*} p<0.05$.

Samples of control and treated cells were then submitted to annexin V-FITC/propidium iodide staining in order to test the effect of the total extract and the $10 \mathrm{~K}$ fraction on phosphatidylserine externalization, as a hallmark of induction of apoptosis, after 24 and $48 \mathrm{~h}$ of treatment. The data obtained showed no difference between control and exposed cells with the almost total absence of apoptotic annexin+/propidium iodide- cells at all times of investigation (Figure 4), demonstrating that programmed cell death was not involved in cytotoxicity. 
The possible impairment of the mitochondrial function was evaluated by checking with the JC1 probe the MMP status following cell exposure to the preparations. As shown in Figure 5, flow cytometric analyses reveal a loss of the MMP in treated cells, the percentage of low red-emitting cells (bottom quadrant) being about $89 \%$ and $81 \%$ after $24 \mathrm{~h}$ exposure and about $73 \%$ and $74 \%$ after $48 \mathrm{~h}$ exposure to total extracts and $10 \mathrm{~K}$ fractions, respectively, vs. approximately $40 \%$ and $45 \%$ in control cells in the two time intervals.

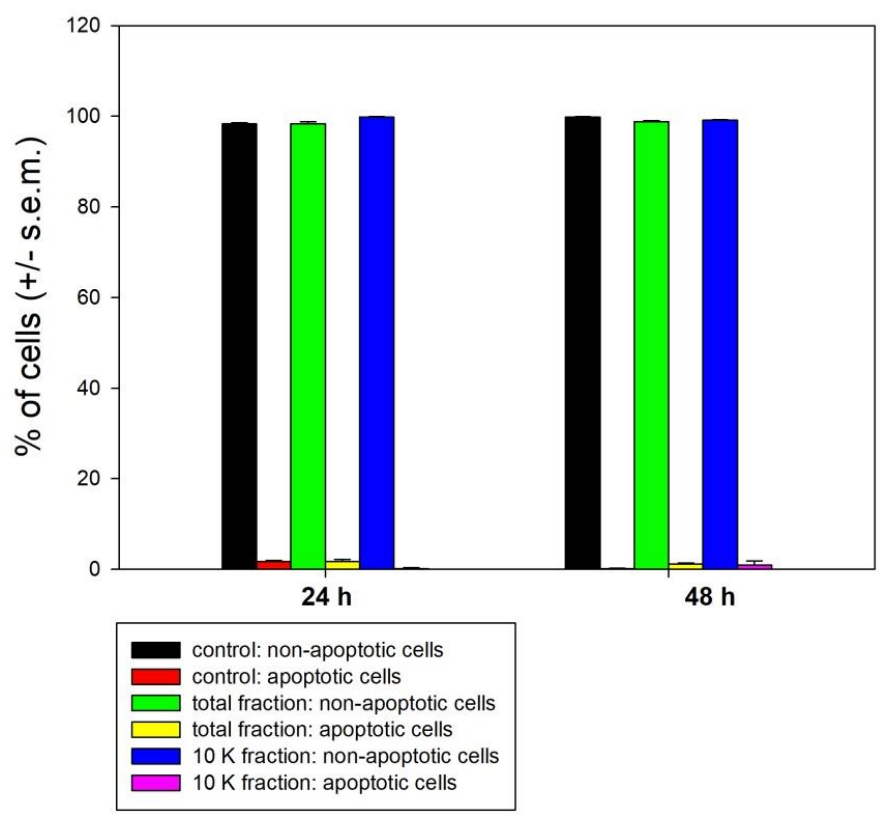

Figure 4. Histograms showing the percentage of apoptotic (annexin V+/propidium iodide-) vs. non-apoptotic MDA-MB-231 cells cultured in control conditions or exposed to either total extracts or $10 \mathrm{~K}$ fractions for 24 and $48 \mathrm{~h}$. Error bars correspond to the standard error of the mean (s.e.m.) of three independent measurements. ${ }^{*} p<0.05$.

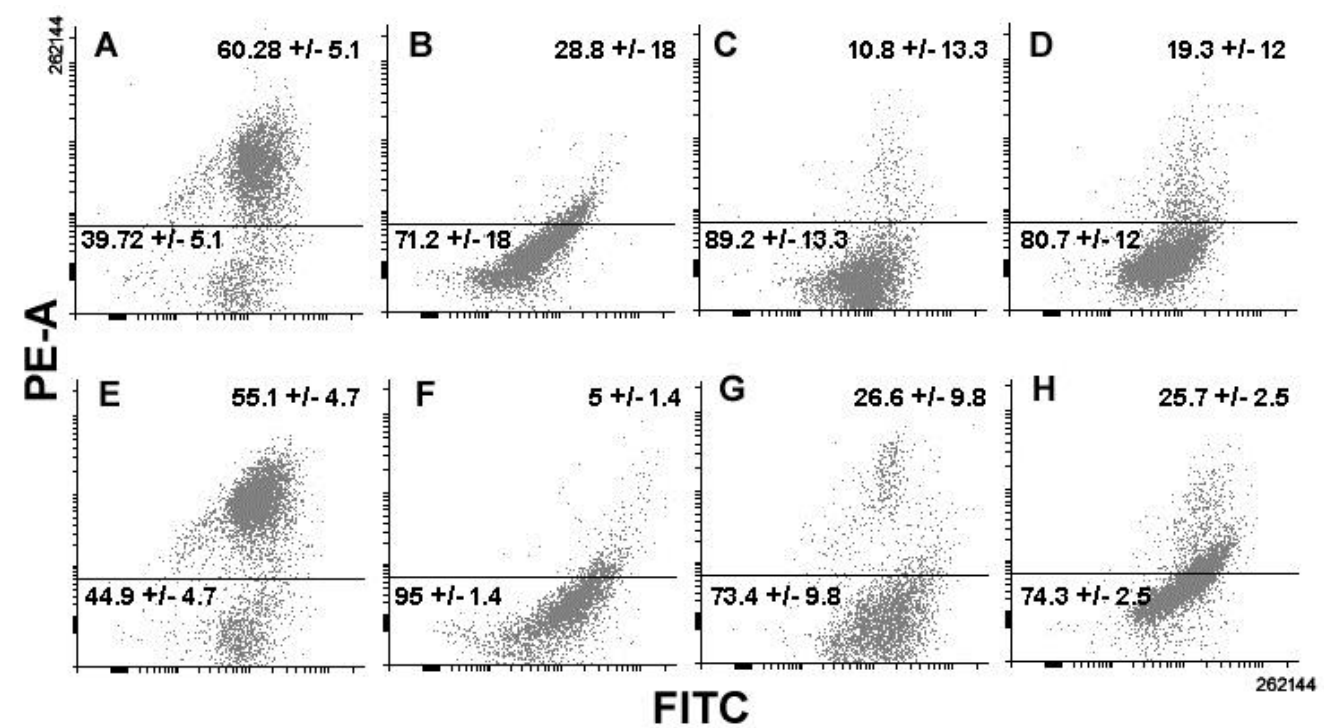

Figure 5. Representative flow cytometric analyses of the transmembrane mitochondrial potential $(\mathrm{MMP})$ in control $(\mathbf{A}, \mathbf{E})$, total extract- $(\mathrm{C}, \mathrm{G})$, and 10K fraction-treated $(\mathbf{D}, \mathbf{H})$ MDA-MB231 cells for 24 (A-D) and $48 \mathrm{~h}(\mathbf{E}-\mathbf{H})$. Dot plots (B) and (F) show the parallel positive controls of valinomycin-treated cells. The values indicated in the bottom quadrants in each frame quantitate the percentage of low red-emitting cells that underwent dissipation of MMP. The results are expressed as mean \pm s.e.m. of triplicate assays. 
The imbalance of cell redox state was assayed via evaluation of ROS production. As shown in Figure 6, after gating to exclude the population of low-fluorescence-emitting dead cells from the analysis, the results obtained indicate that both 24 and $48 \mathrm{~h}$ exposure to total extracts and 10K fractions did not result in the overaccumulation of total intracellular ROS (superoxide anion, hydrogen peroxide, hydroxyl radical and singlet oxygen), being the fluorescence intensities comparable to those of untreated controls and smaller than those of positive controls.
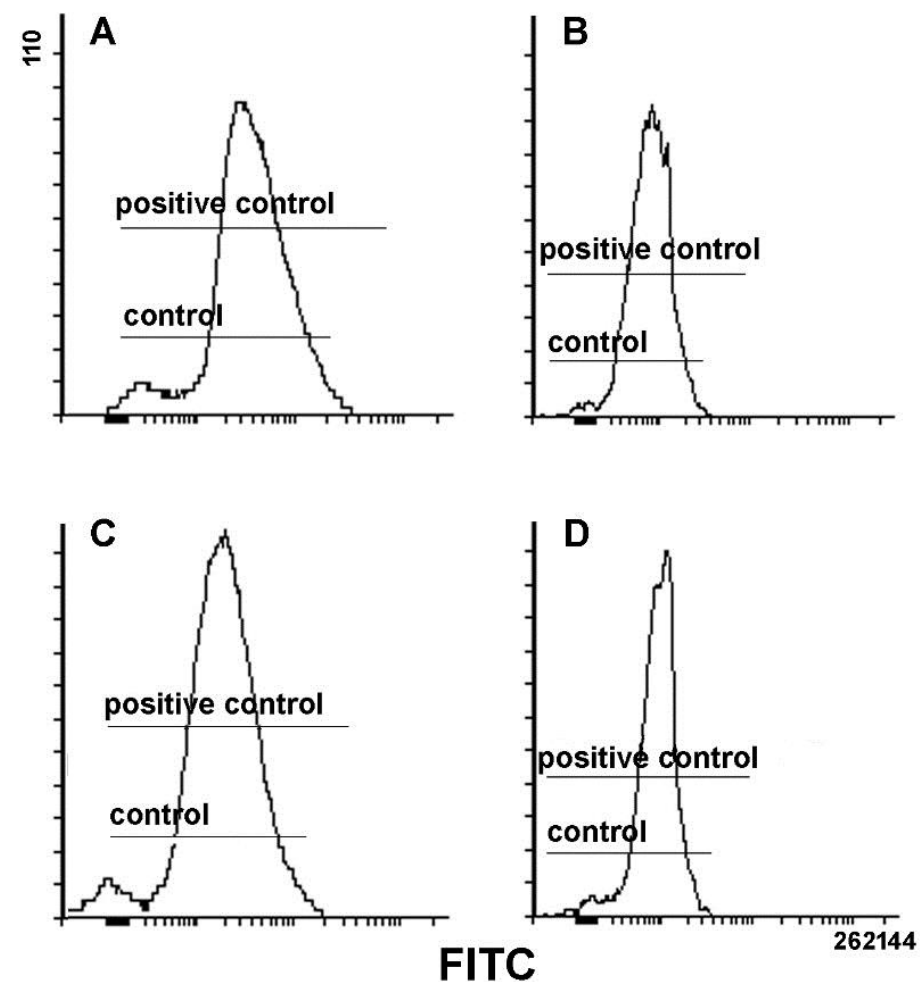

\section{FITC}

Figure 6. Representative plots showing reactive oxygen species (ROS) accumulation in gated alive MDA-MB231 cells exposed to total extracts $(\mathbf{A}, \mathbf{C})$ and $10 \mathrm{~K}$ fractions $(\mathbf{B}, \mathbf{D})$ for $24(\mathbf{A}, \mathbf{C})$ and $48 \mathrm{~h}(\mathbf{B}, \mathbf{D})$, compared to controls and $\mathrm{H}_{2} \mathrm{O}_{2}$-treated cells as positive controls. The $x$-axis reports the intensity of green fluorescence emitted by the dye $2^{\prime}, 7^{\prime}$-dichlorodihydrofluorescein, which is proportional to the amount of cytosolic ROS.

Lastly, we checked whether the CF preparations could exert an effect on the modulation of the autophagic activity by TNBC cells. A first set of assays was performed to evaluate the possible modification in the amount of AVOs, a hallmark of autophagy, through staining with acridine orange, a cell-permeable fluorescent dye that can be captured within the acidic compartments after uptake and protonation. Interestingly, although as already reported, the autophagy rate of the cell line and consequently the amount of red-emitting MDA-MB231 cells are constitutively high [18,19,22]. Figure 7 shows that a further increase of fluorescent events can be observed after exposures to the preparations for 24 and $48 \mathrm{~h}$, being more conspicuous in the presence of the $10 \mathrm{~K}$ fraction upon $24 \mathrm{~h}$ of treatment.

It is widely recognized that acridine orange is a reliable marker for monitoring autophagy only when used in conjunction with other molecular markers [23]. For this reason, to confirm the acridine orange data, we then checked the intracellular accumulation levels of beclin-1, whose increase is a hallmark of the onset of autophagy, and LC3-II, the autophagosome-linked lipidated form of LC3-I protein, whose amount is closely correlated with that of the organelles, thereby being a good indicator of their formation. For LC3-II quantification, unfixed cells were resuspended in saponin-containing buffers before the flow cytometric immunoassays in order to extract and discard the amount of immunoreactive soluble cytosolic LC3-I [21]. In addition, since conflicting evidence exists regarding 
the upregulation of LC3 transcription levels in autophagy-leading conditions of cellular stress [24-26], we also examined the effect of MDA-MB231 cell exposure to total extracts and 10K fractions on the intracellular accumulation of total LC3 via flow cytometric immunoassays performed on fixed cells.
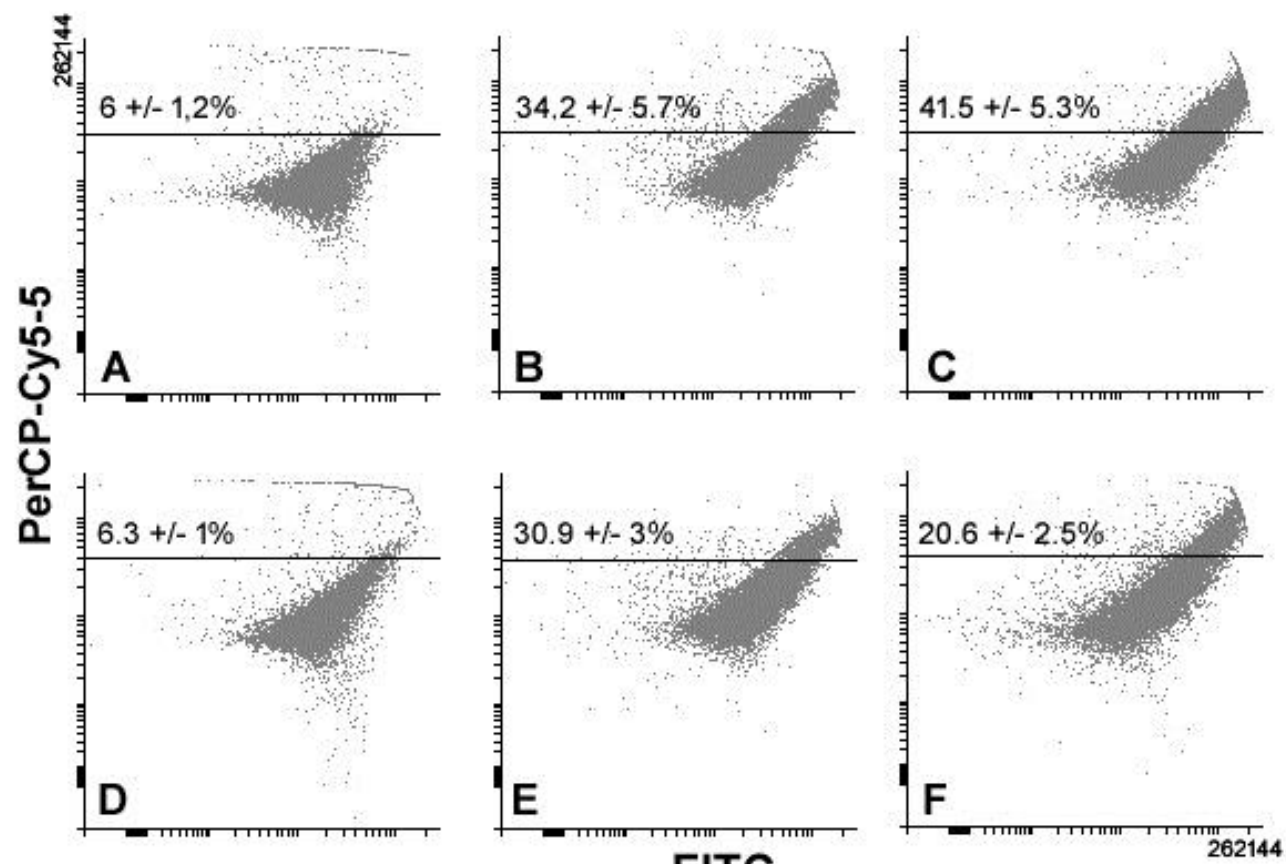

Figure 7. Representative flow cytometric analyses of control (A,D), total extract- (B,E), and 10K fraction-treated (C,F) MDA-MB231 cells stained with acridine orange for evaluation of acidic vesicular organelle (AVO) accumulation after $24(\mathbf{A}-\mathbf{C})$ and $48 \mathrm{~h}(\mathbf{D}, \mathbf{F})$ of exposure. The percentage indicated in the top quadrants refers to the high red fluorescence-emitting events. The results are expressed as mean \pm s.e.m. of triplicate assays.

The histograms in Figure 8 confirm that MDA-MB231 cells have a high basal autophagy level and that an accumulation of autophagy markers may be observed after exposure to the $\mathrm{CF}$ preparations. In fact, control cells display a 1.4- to 2-fold higher LC3-II-related fluorescence intensity than the negative controls, thus indicating a constitutive activation of autophagosome formation in unexposed conditions. On the other hand, the amount of beclin- 1 is further upregulated by about 1.9-fold in the presence of both total extract and $10 \mathrm{~K}$ fraction after $24 \mathrm{~h}$ of treatment, being instead comparable to that of the control at $48 \mathrm{~h}$ of exposure. Also, the LC3-II amount further increases after $24 \mathrm{~h}$ of treatment, more prominently in the presence of the $10 \mathrm{~K}$ fraction (10K fraction: About 3.1-fold; total fraction: 1.3-fold vs. control), whereas after $48 \mathrm{~h}$, although remaining upregulated, it displays a more moderate increase of fluorescence in $10 \mathrm{~K}$ fraction-exposed cells (10K fraction: About 1.4-fold; total fraction: 1.2-fold vs. control). Moreover, flow cytometric immunoassays for total LC3 show a greater intracellular accumulation of the whole amount of the protein at $24 \mathrm{~h}$ of exposure to both preparations, being more conspicuous in the presence of the $10 \mathrm{~K}$ fraction (10K fraction: About 3.6-fold; total fraction: 2.35 -fold vs. control), likely due to an early transcriptional activation. After $48 \mathrm{~h}$ of exposure to the $\mathrm{CF}$ preparations, total LC3 amount is comparable to that of control cells. Cumulatively, our results suggest the occurrence of an early autophagy induction upon cell exposure to CF extracts, followed by a flux decline approximately down to the levels of control samples between 24 and $48 \mathrm{~h}$ of treatment. 


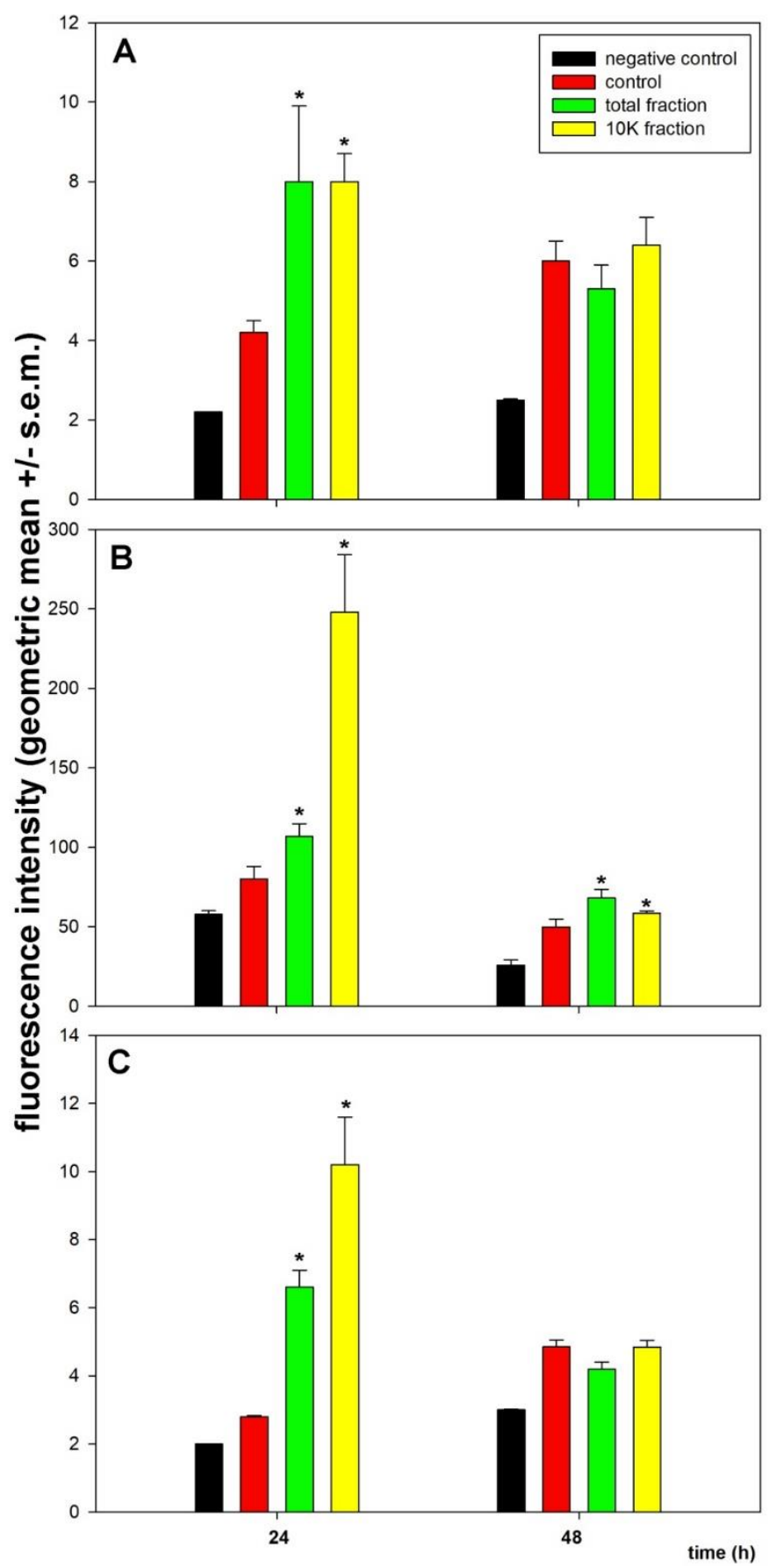

Figure 8. Histograms showing the intensity of the immunofluorescence of beclin-1 (A), LC3-II (B), and total LC3 (C) in control and treated MDA-MB-231 cells after 24 and $48 \mathrm{~h}$ of exposure. Negative controls lack the incubation with the primary antibody. Error bars correspond to the standard error of the mean (s.e.m.) of three independent measurements. ${ }^{*} p<0.05$.

\section{Discussion}

Breast cancer, the most common diagnosed tumour among females, is a widespread neoplastic histotype accounting for about $12 \%$ of all cancers, whose rates are increasing worldwide [27]. Approximately $15 \%$ of breast cancers are of the TNBC subtype, which lacks effective targeted therapies, thereby being regarded as the most aggressive form of breast carcinomas to date [28]. In the attempt to identify novel substances endowed with anti-breast cancer action, here we have tested the cytotoxic effect of aqueous extracts of CFs from H. tubulosa on MDA-MB231 TNBC cells, 
also comparing the activity of the crude extracts to that of the filtered counterparts retaining peptides and other water-soluble components with $\mathrm{MW}<10 \mathrm{kDa}$. Our overall results indicate that although the two preparations play the same biological role, the $10 \mathrm{~K}$ fraction displays a lower $\mathrm{IC}_{50}$ at $24 \mathrm{~h}$ and appears more powerful in acting upon the mitochondrial function and the autophagy rate at $24 \mathrm{~h}$, thus suggesting that the component(s) responsible for such early effects may be more concentrated in the filtered samples.

To our knowledge, here we report the first data linking cell exposure to H. tubulosa-derived extracts to the modulation of the autophagic event. In particular, our results on the initial biological effects that occur $24 \mathrm{~h}$ after cell exposure to the CF extracts highlight autophagy upregulation and MMP dissipation, but with undetectable ROS overproduction, which remains unchanged thereafter. Autophagy, which is a cellular homeostatic function, implicates the autodigestion of cytoplasmic substrates for their removal or turnover after sequestration in the autophagic vacuoles, multi-membrane-bound structures, that then fuse with lysosomes generating AVOs or autolysosomes [29]. The role of autophagy in breast cancer is complex and controversial, since it may operate as a tumor-suppressor mechanism addressing neoplastic cells to death, but, on the other hand, it can act to protect cancer cells in conditions of oxygen and nutrient shortage and allow their rapid proliferative rate by providing energy and basic elements [30]. MDA-MB231 cells are endowed with a constitutively elevated autophagy rate. Inhibition of autophagy was proven to render them susceptible to the lethal effect of chemicals in various experimental conditions (e.g., [18,19,31,32]); on the other hand, lethal effects on this cell line induced by several autophagy inducers have been reported in the literature (e.g., [33,34]).

In this paper, the ability of the preparations under study to modulate the autophagic rate was checked via two different endpoints, i.e., the flow cytometric evaluations of the intracellular accumulations of AVOs and of the protein markers LC3 (total and LC3-II form) and beclin-1, the latter being a key component of the autophagic machinery belonging to the signal-initiating class III phosphatidylinositol-3 kinase complex [35]. Interestingly, the collective data presented here demonstrate that the CF extracts determine autophagy upregulation as indicated by the increase in AVOs, beclin-1, LC3-II, and total LC3, similarly to what was observed for MDA-MB231 in other experimental conditions (e.g., [36,37]). The decrease of the levels of beclin-1 and LC3-II approximately down to those of controls at $48 \mathrm{~h}$ of exposure may reflect their intra-autophagosomal degradation by lysosomal hydrolases after the formation of autophagosomes, whereas that of total LC3 may be due to a decrement in protein synthesis [25,38]. However, it is worth mentioning that acridine orange may also detect lysosomes and is thus not specific to autolysosomes, and assessment of beclin-1 and LC3-II levels is one of the most commonly used markers for autophagy, but as suggested by Klionsky et al. [23], should be coupled to other markers to give exhaustive indication of autophagic activity. Therefore, further studies are required to accurately determine whether autophagy is affected and autophagic activity is modified in CF extracts-treated MDA-MB231 cells.

It is known that treatment of MDA-MB231 cells with compounds that induce mitochondrial dysfunction and loss of MMP selectively results in the activation of autophagy, and that the originated autophagosomes are mainly addressed to engulf the damaged organelles via binding through an endogenous protein complex that contains the proteins LC3-II and Mitofusin 2 [39]. Therefore, our results suggest that the upregulation of autophagy observed after cell exposure to the CF preparations might be, at least in good part, of the "mitophagic" type. This hypothesis is substantiated by the absence of activation of cell death program, as observed after cell exposure to CF preparations. In fact, it is also known that autophagosomal degradation of the damaged mitochondria reduces the intracytoplasmic release of cytochrome $\mathrm{C}$ and inhibits the onset of intrinsic apoptosis [32]. It must also be taken into consideration, however, that MDA-MB-231 cells are provided with a mutant p53 and high levels of phospholipase $\mathrm{D}$, both sustaining survival, thereby being intrinsically resistant to apoptosis $[40,41]$. Moreover, the autophagic clearance of the damaged mitochondria can also determine an interference with ROS production that might account for the inability to detect their increased accumulation in our experimental conditions, as found in other cases of MMP collapse in MDA-MB231 cells [18,19,31]. 
Interestingly, Gonzalez et al. [42] have reported the occurrence of a cytoprotective antioxidant response in MDA-MB231 cells induced by ROS-triggered autophagy upregulation, which implies the onset of a feedback loop between the free radical-protecting Keap1-Nrf2 pathway and the autophagy-related protein Atg7.

Treatment with both CF preparations was shown to exert a selective effect on cell cycle distribution in a later timeframe, i.e., between 24 and $48 \mathrm{~h}$ of exposure, by producing a significant accumulation of MDA-MB231 cells at the S phase. It is conceivable that cells, increasingly damaged during the early times of exposure to the CF extracts, in this time lapse start to meet failures in DNA replication activity with a consequent slowing down of the specific cycle phase, if not an arrest, compared to controls [43]. It is worth mentioning that substances that promote autophagy are also known to alter the progression of the cell cycle preferentially in the S phase (e.g., [44,45]). Interestingly, the restraining property of the CF extracts from $H$. tubulosa reported here is shared with the aqueous extracts from another Mediterranean Sea cucumber, i.e., Holothuria polii, which were found to arrest MDA-MB231 cells in the S phase after three days of exposure [46].

Further elucidation of these and other autophagy-related molecular circuits through which the extracts of H. tubulosa CF accomplish their TNBC cell death activity will be carried out in future studies. Nonetheless, our work presents interesting aspects in that it expands the list of the preparations of natural origin that upregulate autophagy, while inhibiting tumor cell viability and provides more insight into the role played by autophagy in breast cancer cell death. It is indeed known that other echinoderms, including the Holothurian species, produce small molecules or amino acids that are able to induce autophagy in cancer cells [47-49].

A limitation of this study is the lack of identification of the CF component(s) responsible for the observed effects, which has/have not been isolated to date. On the other hand, the data reported here strongly suggest that such water-soluble constituent(s) is/are resistant to lyophilization, resuspension, and freeze-thawing cycles, and must supposedly have a MW $<10 \mathrm{kDa}$ since the biological activity is retained and ameliorated after filtration of the crude extract. In light of the literature data, sea cucumber-derived anti-cancer molecules that exhibit this size fall into the categories of triterpenes, glycosaminoglycans, and peptides [8,50]. At present, we cannot exclude the existence of potential synergic activities, as reported by Guo et al. [51].

A great deal of literature data have widely discussed the molecular nature of potential anti-cancer compounds obtained from sea cucumbers [52]. Notably, the majority of them consist of molecules recovered after fractionation of extracts in organic solvents, and hence our work adds one more reference to the limited number of publications that instead focus on the cytotoxic activity of aqueous extracts and their components (e.g., $[46,53,54])$.

\section{Conclusions}

In summary, we have shown that extracts from H. tubulosa CF are cytotoxic towards TNBC cells in vitro and therefore merit further investigation aimed at the characterization of the "active ingredient(s)" present in the samples under study to develop novel promising prevention and/or treatment agents efficacious against highly metastatic breast carcinomas.

Author Contributions: D.R., D.M.L.A., V.L., F.A., M.C., and V.A. performed the experiments. C.L. and M.V. supervised the work and wrote the paper.

Funding: This research was funded by The University of Palermo (Italy), grant Fondo Finalizzato alla Ricerca (FFR) 2018 to C.L. and M.V.

Conflicts of Interest: The authors declare no conflict of interest.

\section{References}

1. Bordbar, S.; Anwar, F.; Saari, N. High-value components and bioactives from sea cucumbers for functional foods-A review. Mar. Drugs 2011, 9, 1761-1805. [CrossRef] [PubMed] 
2. Correia-da-Silva, M.; Sousa, E.; Pinto, M.M.M.; Kijjoa, A. Anticancer and cancer preventive compounds from edible marine organisms. Semin. Cancer Biol. 2017, 46, 55-64. [CrossRef] [PubMed]

3. Mamelona, J.; Pelletier, E.M.; Lalancette, K.G.; Legault, J.; Karboune, S.; Kermasha, S. Quantification of phenolic contents and antioxidant capacity of Atlantic sea cucumber, Cucumaria frondosa. Food Chem. 2007, 104, 1040-1047. [CrossRef]

4. Chen, J. Overview of sea cucumber farming and sea ranching practices in China. SPC Beche-de-mer Inf. Bull. 2003, 18, 18-23.

5. Wen, J.; Hu, C.; Fan, S. Chemical composition and nutritional quality of sea cucumbers. J. Sci. Food Agric. 2010, 90, 2469-2474. [CrossRef] [PubMed]

6. Pangestuti, R.; Arifin, Z. Medicinal and health benefit effects of functional sea cucumbers. J. Tradit. Complement. Med. 2017, 8, 341-351. [CrossRef] [PubMed]

7. Yang, W.; Cai, Y.; Yin, R.; Lin, L.; Li, Z.; Wu, M.; Zhao, J. Structural analysis and anticoagulant activities of two sulfated polysaccharides from the sea cucumber Holothuria coluber. Int. J. Biol. Macromol. 2018, 115, 1055-1062. [CrossRef] [PubMed]

8. Khotimchenko, Y. Pharmacological potential of sea cucumbers. Int. J. Mol. Sci. 2018, 19, 1342. [CrossRef]

9. Aysola, K.; Desai, A.; Welch, C.; Xu, J.; Qin, Y.; Reddy, V.; Matthews, R.; Owens, C.; Okoli, J.; Beech, D.J.; et al. Triple negative breast cancer - an overview. Hereditary Genet. 2013, 2013 (Suppl. 2). [CrossRef]

10. Rakaj, A.; Fianchini, A.; Boncagni, P.; Lovatelli, A.; Scardi, M.; Cataudella, S. Spawning and rearing of Holothuria tubulosa: A new candidate for aquaculture in the Mediterranean region. Aquac. Res. 2018, 49, 557-568. [CrossRef]

11. Herencia, F.; Ubeda, A.; Ferrándiz, M.L.; Terencio, M.C.; Alcaraz, M.J.; García-Carrascosa, M.; Capaccioni, R.; Payá, M. Anti-inflammatory activity in mice of extracts from Mediterranean marine invertebrates. Life Sci. 1998, 62, PL115-PL120. [CrossRef]

12. Schillaci, D.; Cusimano, M.G.; Cunsolo, V.; Saletti, R.; Russo, D.; Vazzana, M.; Vitale, M.; Arizza, V. Immune mediators of sea-cucumber Holothuria tubulosa (Echinodermata) as source of novel antimicrobial and anti-staphylococcal biofilm agents. AMB Express 2013, 3, 35. [CrossRef] [PubMed]

13. Vazzana, M.; Celi, M.; Chiaramonte, M.; Inguglia, L.; Russo, D.; Ferrantelli, V.; Battaglia, D.; Arizza, V. Cytotoxic activity of Holothuria tubulosa (Echinodermata) coelomocytes. Fish Shellfish Immunol. 2018, 72, 334-341. [CrossRef]

14. Luparello, C.; Romanotto, R.; Tipa, A.; Sirchia, R.; Olmo, N.; López de Silanes, I.; Turnay, J.; Lizarbe, M.A.; Stewart, A.F. Midregion parathyroid hormone-related protein inhibits growth and invasion in vitro and tumorigenesis in vivo of human breast cancer cells. J. Bone Miner. Res. 2001, 16, 2173-2181. [CrossRef] [PubMed]

15. Gartel, A.L.; Feliciano, C.; Tyner, A.L. A new method for determining the status of p53 in tumor cell lines of different origin. Oncol. Res. 2003, 13, 405-408. [CrossRef] [PubMed]

16. Huovinen, M.; Loikkanen, J.; Myllynen, P.; Vähäkangas, K.H. Characterization of human breast cancer cell lines for the studies on p53 in chemical carcinogenesis. Toxicol. In Vitro 2011, 25, 1007-1017. [CrossRef]

17. Longo, A.; Librizzi, M.; Chuckowree, I.S.; Baltus, C.B.; Spencer, J.; Luparello, C. Cytotoxicity of the urokinase-plasminogen activator inhibitor carbamimidothioic acid (4-boronophenyl) methyl ester hydrobromide (BC-11) on triple-negative MDA-MB231 breast cancer cells. Molecules 2015, 20, 9879-9889. [CrossRef]

18. Librizzi, M.; Longo, A.; Chiarelli, R.; Amin, J.; Spencer, J.; Luparello, C. Cytotoxic effects of Jay Amin hydroxamic acid (JAHA), a ferrocene-based class I histone deacetylase inhibitor, on triple-negative MDA-MB231 breast cancer cells. Chem. Res. Toxicol. 2012, 25, 2608-2616. [CrossRef]

19. Luparello, C.; Asaro, D.M.L.; Cruciata, I.; Hassell-Hart, S.; Sansook, S.; Spencer, J.; Caradonna, F. Cytotoxic activity of the histone deacetylase 3-selective inhibitor Pojamide on MDA-MB-231 triple-negative breast cancer cells. Int. J. Mol. Sci. 2019, 20, 804. [CrossRef]

20. He, Y.; Mo, Z.; Xue, Z.; Fang, Y. Establish a flow cytometric method for quantitative detection of Beclin-1 expression. Cytotechnology 2013, 65, 481-489. [CrossRef]

21. Eng, K.E.; Panas, M.D.; Karlsson Hedestam, G.B.; McInerney, G.M. A novel quantitative flow cytometry-based assay for autophagy. Autophagy 2010, 6, 634-641. [CrossRef] [PubMed] 
22. Garbar, C.; Mascaux, C.; Giustiniani, J.; Merrouche, Y.; Bensussan, A. Chemotherapy treatment induces an increase of autophagy in the luminal breast cancer cell MCF7, but not in the triple-negative MDA-MB231. Sci. Rep. 2017, 7, 7201. [CrossRef] [PubMed]

23. Klionsky, D.J.; Abdelmohsen, K.; Abe, A.; Abedin, M.J.; Abeliovich, H.; Acevedo Arozena, A.; Adac, H.; Adams, C.M.; Adams, P.D.; Adeli, K.; et al. Guidelines for the use and interpretation of assays for monitoring autophagy (3rd edition). Autophagy 2016, 12, 1-222. [CrossRef] [PubMed]

24. Mizushima, N.; Yoshimori, T. How to interpret LC3 immunoblotting. Autophagy 2007, 3, 542-545. [CrossRef] [PubMed]

25. Tanida, I.; Minematsu-Ikeguchi, N.; Ueno, T.; Kominami, E. Lysosomal turnover, but not a cellular level, of endogenous LC3 is a marker for autophagy. Autophagy 2005, 1, 84-91. [CrossRef] [PubMed]

26. He, C.; Klionsky, D.J. Regulation mechanisms and signaling pathways of autophagy. Annu. Rev. Genet. 2009, 43, 67-93. [CrossRef]

27. Bray, F.; Ferlay, J.; Soerjomataram, I.; Siegel, R.L.; Torre, L.A.; Jemal, A. Global cancer statistics 2018: GLOBOCAN estimates of incidence and mortality worldwide for 36 cancers in 185 countries. CA Cancer J. Clin. 2018, 68, 394-424. [CrossRef]

28. Saraiva, D.P.; Guadalupe Cabral, M.; Jacinto, A.; Braga, S. How many diseases is triple negative breast cancer: The protagonism of the immune microenvironment. ESMO Open 2017, 2, e000208. [CrossRef]

29. Yin, Z.; Pascual, C.; Klionsky, D.J. Autophagy: Machinery and regulation. Microb. Cell 2016, 3, 588-596. [CrossRef]

30. Yun, C.W.; Lee, S.H. The roles of autophagy in cancer. Int. J. Mol. Sci. 2018, 19, 3466. [CrossRef]

31. Librizzi, M.; Spencer, J.; Luparello, C. Biological effect of a hybrid anticancer agent based on kinase and histone deacetylase inhibitors on triple-negative (MDA-MB231) breast cancer cells. Int. J. Mol. Sci. 2016, 17, 1235. [CrossRef]

32. Guo, W.; Wang, Y.; Wang, Z.; Wang, Y.P.; Zheng, H. Inhibiting autophagy increases epirubicin's cytotoxicity in breast cancer cells. Cancer Sci. 2016, 107, 1610-1621. [CrossRef] [PubMed]

33. Yang, F.; Wang, F.; Liu, Y.; Wang, S.; Li, X.; Huang, Y.; Xia, Y.; Cao, C. Sulforaphane induces autophagy by inhibition of HDAC6-mediated PTEN activation in triple negative breast cancer cells. Life Sci. 2018, 213, 149-157. [CrossRef] [PubMed]

34. Tian, L.; Cheng, F.; Wang, L.; Qin, W.; Zou, K.; Chen, J. CLE-10 from Carpesium abrotanoides L. suppresses the growth of human breast cancer cells (MDA-MB-231) in vitro by inducing apoptosis and pro-death autophagy via the PI3K/Akt/mTOR signaling pathway. Molecules 2019, 24, 1091. [CrossRef]

35. Toton, E.; Lisiak, N.; Sawicka, P.; Rybczynska, M. Beclin-1 and its role as a target for anticancer therapy. J. Physiol. Pharmacol. 2014, 65, 459-467.

36. Chang, L.C.; Hsieh, M.T.; Yang, J.S.; Lu, C.C.; Tsai, F.J.; Tsao, J.W.; Chiu, Y.J.; Kuo, S.C.; Lee, K.H. Effect of bis(hydroxymethyl) alkanoate curcuminoid derivative MTH-3 on cell cycle arrest, apoptotic and autophagic pathway in triple-negative breast adenocarcinoma MDA-MB-231 cells: An in vitro study. Int. J. Oncol. 2018, 52, 67-76. [CrossRef]

37. Nel, M.; Joubert, A.M.; Dohle, W.; Potter, B.V.; Theron, A.E. Modes of cell death induced by tetrahydroisoquinoline-based analogs in MDA-MB-231 breast and A549 lung cancer cell lines. Drug Des. Devel. Ther. 2018, 12, 1881-1904. [CrossRef] [PubMed]

38. Cosse, J.P.; Rommelaere, G.; Ninane, N.; Arnould, T.; Michiels, C. BNIP3 protects HepG2 cells against etoposide-induced cell death under hypoxia by an autophagy-independent pathway. Biochem. Pharmacol. 2010, 80, 1160-1169. [CrossRef]

39. Biel, T.G.; Rao, V.A. Mitochondrial dysfunction activates lysosomal-dependent mitophagy selectively in cancer cells. Oncotarget 2017, 9, 995-1011. [CrossRef]

40. Zheng, Y.; Rodrik, V.; Toschi, A.; Shi, M.; Hui, L.; Shen, Y.; Foster, D.A. Phospholipase D couples survival and migration signals in stress response of human cancer cells. J. Biol. Chem. 2006, 281, 15862-15868. [CrossRef] [PubMed]

41. Gurtner, A.; Starace, G.; Norelli, G.; Piaggio, G.; Sacchi, A.; Bossi, G. Mutant p53-induced up-regulation of mitogen-activated protein kinase kinase 3 contributes to gain of function. J. Biol. Chem. 2010, 285, 14160-14169. [CrossRef]

42. Gonzalez, Y.; Aryal, B.; Chehab, L.; Rao, V.A. Atg7- and Keap1-dependent autophagy protects breast cancer cell lines against mitoquinone-induced oxidative stress. Oncotarget 2014, 5, 1526-1537. [CrossRef] [PubMed] 
43. Chao, H.X.; Poovey, C.E.; Privette, A.A.; Grant, G.D.; Chao, H.Y.; Cook, J.G.; Purvis, J.E. Orchestration of DNA damage checkpoint dynamics across the human cell cycle. Cell Syst. 2017, 5, 445-459. [CrossRef] [PubMed]

44. Tasdemir, E.; Maiuri, M.C.; Tajeddine, N.; Vitale, I.; Criollo, A.; Vicencio, J.M.; Hickman, J.A.; Geneste, O.; Kroemer, G. Cell cycle-dependent induction of autophagy, mitophagy and reticulophagy. Cell Cycle 2007, 6, 2263-2267. [CrossRef] [PubMed]

45. Guo, Y.; Pei, X. Tetrandrine-induced autophagy in MDA-MB-231 triple-negative breast cancer cell through the inhibition of PI3K/AKT/mTOR signaling. Evid. Based Complem. Altern. Med. 2019, 2019, 7517431. [CrossRef] [PubMed]

46. Kareh, M.; El Nahas, R.; Al-Aaraj, L.; Al-Ghadban, S.; Naser Al Deen, N.; Saliba, N.; El-Sabban, M.; Talhouk, R. Anti-proliferative and anti-inflammatory activities of the sea cucumber Holothuria polii aqueous extract. SAGE Open Med. 2018, 6, 2050312118809541. [CrossRef] [PubMed]

47. Russo, G.L.; Russo, M.; Castellano, I.; Napolitano, A.; Palumbo, A. Ovothiol isolated from sea urchin oocytes induces autophagy in the Hep-G2 cell line. Mar. Drugs 2014, 12, 4069-4085. [CrossRef]

48. Castellano, I.; Seebeck, F.P. On ovothiol biosynthesis and biological roles: From life in the ocean to therapeutic potential. Nat. Prod. Rep. 2018, 35, 1241-1250. [CrossRef] [PubMed]

49. Brancaccio, M.; Russo, M.; Masullo, M.; Palumbo, A.; Russo, G.L.; Castellano, I. Sulfur-containing histidine compounds inhibit gamma-glutamyl transpeptidase activity in human cancer cells. J. Biol. Chem. 2019, 294, 14603-14614. [CrossRef] [PubMed]

50. Bahrami, Y.; Zhang, W.; Franco C, M.M. Distribution of saponins in the sea cucumber Holothuria lessoni; the body wall versus the viscera, and their biological activities. Mar. Drugs. 2018, 16, 423. [CrossRef]

51. Guo, Y.; Han, X.; Che, H.; Li, Z.; Dong, P.; Xue, C.; Zhang, T.; Wang, Y. Synergistic effect of eicosapentaenoic acid-enriched phospholipids and sea cucumber saponin on orotic acid-induced non-alcoholic fatty liver disease in rats. R. Soc. Open Sci. 2018, 5, 172182. [CrossRef] [PubMed]

52. Janakiram, N.B.; Mohammed, A.; Rao, C.V. Sea cucumbers metabolites as potent anti-cancer agents. Mar. Drugs 2015, 13, 2909-2923. [CrossRef] [PubMed]

53. Wijesinghe, W.A.; Jeon, Y.J.; Ramasamy, P.; Wahid, M.E.; Vairappan, C.S. Anticancer activity and mediation of apoptosis in human HL-60 leukaemia cells by edible sea cucumber (Holothuria edulis) extract. Food Chem. 2013, 139, 326-331. [CrossRef] [PubMed]

54. Baharara, J.; Amini, E.; Afzali, M.; Nikdel, N.; Mostafapour, A.; Kerachian, M.A. Apoptosis inducing capacity of Holothuria arenicola in CT26 colon carcinoma cells in vitro and in vivo. Iran. J Basic Med. Sci. 2016, 19, 358-365. [PubMed]

(C) 2019 by the authors. Licensee MDPI, Basel, Switzerland. This article is an open access article distributed under the terms and conditions of the Creative Commons Attribution (CC BY) license (http://creativecommons.org/licenses/by/4.0/). 